\title{
Kişilerarası Gerilimin Örgütsel Hafıza Üzerindeki Etkisi: Bir Alan Araştırması
}

\author{
$* * *$

\section{The Impact of Interpersonal Strain at Work on Organizational Memory: An Empirical Study}

\author{
Doç. Dr. Fikret Sözbilir \\ Artvin Çoruh Üniversitesi, Hopa İIBF, fsozbilir08@hotmail.edu.tr \\ ORCID: 0000-0003-2665-1795
}

\section{Berçem Yaman}

Artvin Çoruh Üniversitesi, LEE İşletme ABD Yüksek Lisans Öğrencisi, brcmymn@gmail.com ORCID: 0000-0003-0074-9372

\section{Özet}

Çalışmanın amacı, işte kişilerarası gerilimin örgütsel hafıza üzerindeki etkisini incelemektir. Ayrıca, sonuçlara dayalı olarak önerilerde bulunmak da amaçlanmıştır. Konu edinilen teorik modelin analizi için Arhavi'deki okullarda çalışan 128 öğretmen örneklem olarak belirlenmiş ve veriler bir anket aracılığıyla toplanmıştır. Veriler SPSS 25.0 programıla Pearson korelasyon ve basit doğrusal regresyon testleri uygulanarak analiz edilmiş ve tablolar halinde sunulmuştur. Sonuçlar, kişilerarası gerilimin örgütsel hafıza üzerinde olumsuz ve anlamlı bir etkisi olduğunu ortaya çıkarmıştır. Çalışma sonucunda, yöneticilerin örgütsel hafızayı geliştirmek için işte kişilerarası gerilimi önlemeye dikkat etmesi gerektiği anlaşılmıştır.

Anahtar Kelimeler: Kişilerarası gerilim, Örgütsel hafıza, Öğrenme, Bilgi paylaşımı.

JEL Sinıflandırması: M12, M50, D23, L20

\begin{abstract}
The aim of study was to examine the impact of the interpersonal strain at work on organizational memory. In addition, it aimed to make suggestions based on results. For analysis of the proposed theoretical model, 128 teachers, employed in schools in Arhavi, were sampled and the data were gathered by means of a questionnaire. The data was analyzed with the SPSS 25.0 software by conducting Pearson correlation and simple linear regression analyzes and presented in tables. The results revealed that the interpersonal strain at work has a negative and significant impact on organizational memory. The study concluded that managers should pay attention to prevent interpersonal strain at work in order to develop organizational memory.
\end{abstract}

Keywords: Interpersonal strain, Organizational memory, Learning, Knowledge sharing.

JEL Classification: M12, M50, D23, L20

\section{GíRİ̧̧}

Günümüz iş dünyasında yaşanan yoğun iş temposunda pek çok faktör çalışanların iş arkadaşları ve örgütleri ile ilişkilerini çok yönlü etkilemektedir. Bunlardan ikisi kişilerarası gerilim ve örgütsel hafızadır. Kişilerarası gerilim tükenmişlik ve motivasyon bozukluğundan kaynaklanan insan ilişkilerinde bozulma olarak görülmektedir (Consiglio, 2014). Daha önce işte kişilerarası gerilimi, sinizm ve tükenmişlik duygularıyla ilişkilendirerek çalışmalar yapılmış bu kavramlarla yakın ilişkisi vurgulanmıştır (Borgogni, Consiglio, Alessandri, \& Schaufeli, 2012). Sosyal etkileşimin gereği olarak karş1lık verilmesi gereken diyalogdan kaçınma olarak ifade edilen sosyal geri çekilme davranışı (Eldridge \& Christensen, 2002) ile de yakın benzerlik gösteren işte kişilerarası gerilim; iş yerinde arkadaşları ile yüz yüze gelmekten kaçınma, uzak durma ve iletişim kurmama (Caughlin \& Huston, 2002) bireyin örgütsel anlamda oluşturulacak sinerjiye katkıda bulunmaması anlamına da gelir. Bir başka asosyal davranış şekli olarak bireyin sürekli 
çevresindekilerden uzak durma ve onlarla ilgilenmeme tavrı diye kavramlaştırılan duyarsızlaşma (Salanova, \& Schaufeli, 2000; Maslach, Schaufeli, \& Leiter, 2001) durumu da işte kişilerarası gerilime referans olacak bir davranış şeklidir. Benzer bir durum olan duygusal uyumsuzluk, hissedilen ile sergilenen duygusal ifadenin tutarsızlığ (Zapf, 2002; Hochschild, 2012) ve kişi-rol çatışması (Rafaeli \& Sutton, 1987; Abraham, 1998) olarak görülür. Duygusal uyumsuzluk işte kişilerarası gerilimin altyapısını oluşturan başka bir davranış tarzı olup, tükenmişliği artırmasına ve iş tatminini azaltmasına (Zapf, 2002) karşın başka bir araştırmada ise işine ve işinin gereklerine duyarlı çalışanlarda kişisel başarıyı olumlu etkilediği belirlenmiştir (Zapf, \& Holz, 2006). İşte kişilerarası gerilim ile duygusal uyumsuzluk (emotional dissonance) arasında dolaylı pozitif ilişki olduğu ise ayrı bir gerçektir (Consiglio, 2014).

Örgütsel hafiza en yalın ifade ile örgütün arşivi olarak nitelendirilebilir. Stein'e göre (1995), örgütün etkinliğini artırmada ve dolayısıyla rekabetçi üstünlük kazanmasında anahtar role sahip olan örgütsel hafıza, aynı zamanda örgütün geçmişini geleceğine bağlayan soyut bir köprüdür. Örgütsel hafiza, örgütün kültüründe ve örgütün üyelerinin zihinlerinde var olan yapılandırılmış ve yapılandırılmamış kavramlar, birikimler ve bilgilerden oluşmaktadır. Bunlar veri tabanlarında, bilgisayar kayıtlarında ve dosyalarda tutulur (Jennex \& Olfman, 2004). Jackson (2010) örgütsel hafizayı, bilgiyi ortak kullanıma sokmak için bireyin aklında kapalı olmaktan çıkarıp durum değerlendirme, yenileşim, bilgi arama, derleme ve depolama faaliyetleri ile edinilen örgütsel bilgi yönetimi süreci olarak görür. Bu şekilde gerçekleşmiş sonuçları ve öğrenilen bilgileri kayıt altına alınarak işletmelerin faaliyetlerinde aynı hatayı tekrar etmeme, yeni ortaya çıkan hataları kolayca tespit etme, çözüm bulma ve önlem almada çözüm kaynağıdır (Vrîncianu, AnicaPopa, \& Anica-Popa, 2009; Uğurlu, 2011). Anand, Manz ve Glick (1998), örgütsel hafiza oluşturma ve ondan yararlanmada bilgi yönetiminin klasik yaklaşımı ile çalışanlara aşırı bilgi yükleme yerine değişik kaynaklarda var olan ve ihtiyaç duyulan enformasyon hakkında çalışanları bilgilendirip gerektiğinde ona erişimini kolaylaştırmanın daha etkili olacağını öne sürmüşlerdir. Güçlü bir örgütsel hafıza oluşturmak için sistemli ve etkin bir örgütsel öğrenme en önemli unsurdur. Örgütsel öğrenme için örgüt üyeleri arasında etkin bir iletişim kanalıyla bilgi paylaşımı gereklidir (Hedberg, 1981; Walsh \& Ungson, 1991; Hult \& Ferrell, 1997; Senge, 2006; Vrîncianu, Anica-Popa, \& Anica-Popa, 2009; Camisón \& Villar-López, 2011; Uğurlu, 2012).

Bu çalışmanın amacı daha önce yapılan çalı̧̧malarda yeterince araştırılmamış olan işte kişilerarası gerilimin örgütsel hafıza üzerindeki etkisini incelemektir. Bu yüzden, bu alandaki mevcut ancak sinırlı literatür incelenmiş ve doğrudan 'işte kişilerarası gerilim' ve 'örgütsel hafiza' ilişkisi veya etkileşiminin araştırılmadığı belirlenmiş ve literatürde söz konusu önemli açığın giderilmesi bakımından bu çalışma literatüre katkı sağlayacaktır.

\section{KAVRAMSAL ÇERÇEVE}

\section{1. İşte Kişilerarası Gerilim}

İşte kişilerarası gerilim, iş yerindeki insanların aşırı bir şekilde sosyal istekleri ve baskılarından duyulan rahatsızlık hissi ve ilişkilerin kopması durumunu ifade eder (Borgogni vd. 2012). Borgogni vd. (2012) kişilerarası gerilimi, kişinin bireylerarası aşırı beklentiler ve sosyal baskılardan kaynaklı olarak işteki diğer insanlardan duygusal ve bilişsel olarak ayrılma şeklindeki belirgin tepkisi olarak tanımlanmıştır. Başka bir ifade ile organizasyonun içinden ve dışından gelen ve baş edebilmek için çaba gerektiren talepkâr ilişkiler ve sosyal baskılara karşı kendini korumaya yönelik bir tepki de denilebilir. Kişilerarası gerilim kavramı, sosyal ilişkilerde talepkâr yaklaşıma karşı tepki ve kaçınma bağlamında sosyal çekilme kavramı ile de ilgilidir (Eldridge \& Christensen, 2002). Kişilerarası gerilimin duyarsızlaşma ve sinizm ile benzerliği olsa da bazı yönlerden farklılık göstermektedir. Ortak noktaları 'zihinsel uzaklaşma' olarak kavramlaştırılmıştır (Maslach vd., 2001). Kişilerarası gerilim 'diğer insanlarla' ilgili iken sinizm 'işin kendisi' veya örgütle ilgilidir. Duyarsızlaşma ise bireyin kendisini karşılaştığı olumsuzluklardan soyutlaması şeklinde görülür 
(Leiter \& Maslach, 2016) Ancak, her iki kavram da mesleki tükenmişliği tanımlayan faktörlerdendir (Borgogni vd., 2012; Consiglio, 2014; Olusa, \& Afolabi, 2017).

\section{2. Örgütsel Hafıza}

Örgütler bireylerden bağımsız olarak da var olabilirler. Ancak bireylerden bağımsız olmak için her ne kadar akıllı sistemler ve yapay zekâ kullansalar da bu sistemlerin de bireyler tarafından geliştirildiğini ve bireylerin bilgi edinip problem çözme ve karar verme faaliyetlerinde anahtar faktör olduğu unutulmamalıdır. Başarılı bir bilgi yönetimi süreci ile güçlendirilen örgütsel hafiza örgüt bünyesindeki bireylerin bilgilerinin belli bir zamanla sınırlı olmadan bütünleşik bir şekilde organize edilmesi halinde örgüt için önemli katkılar sağlayacaktır. Literatürde değişik tanımları yapılan örgütsel hafıza, Walsh ve Ungson (1991, s. 61) tarafından "şimdiki kararları alabilmek için örgütün tarihinden getirebildiği depolanmış bilgi” olarak tanımlanmıştır. Te’eni’ye göre (2011) örgütsel hafıza bilgi yönetiminde bilgiyi edinme, depolama ve kullanma olduğu gibi enformasyon toplama ve örgütte mevcut olan bilgi için kullanılan genel bir terimdir. Bencsik, Lire ve Marosi (2009, s. 1701) örgütsel hafızayı "zaman içerisinde birbirleri ile bağlantı kuran farklı gruplardan toplanan ve insanların grup hafizası olarak nitelenen bir tür ortak hafıza" şeklinde tanımlamıştır. Çalışanların her birinden derlenen ve kaydedilen örgütsel iş süreçlerinde gerek duyuldukça kullanılan geçmiş deneyimlerden öğrenilmiş bilgilerin bulunduğu ortam örgütsel hafızadır (Walsh \& Ungson, 1991). Yukarıdaki tanımların her biri örgütsel hafızanın bir yönünü vurgulamakla birlikte ortak nokta olarak örgütün aynı hataları tekrarlamaması ve ihtiyaç duyduğu bilgiyi tekrar kullanabilmesi için onu depolaması vurgulanmaktadır. Bunu öne çıkaran ve yapılan daha kapsamlı tanıma göre örgütsel hafıza, organizasyonda bilginin depolandığı, şimdi ve sonra kullanmak için yeniden erişim sağlandığ 1 ve böylece organizasyonun geleceğini tasarlama ve oluşturma sürecine önemli katkılar sağlayan fonksiyonudur (Jasimuddin, Connell \& Klein, 2009). Örgütsel hafizada yer alan bilginin taklit edilmesi ve çalınmasının zor olduğu (Camison \& Villar-Lopez, 2011) ve inovasyona destek olduğu (Moorman \& Miner, 1997; Hanvanich, Sivakumar \& Hult, 2006; Tsai, 2008) için rekabetçi avantaj kazanmada örgüte yararlı olmakta ve örgüt için değerli bir unsur olarak görülmektedir. Örgütsel hafızanın oluşmasında örgütsel öğrenme en önemli işleve sahiptir. Organizasyonun bilgi işleme kapasitesi olarak tanımlanan örgütsel öğrenme bilgiyi yaratma, edinme, aktarma/paylaşma ve bütünleştirme yoluyla gerçekleştirilmekte ve örgütsel hafizayı oluşturmaktadır (Jerez-Gómez, Céspedes-Lorente, Valle-Cabrera, 2005). Böyle bir bilgi organizasyon çerçevesinde öğrenme bireysel düzeyi aşarak örgütsel bir sistematik yapı içerisinde gerçekleşir ve örgütteki kilit personel ayrılsa bile orada kullandıkları her bilgi örgütün hafızasına kaydedilmiş olur. Örgütsel hafizanın gerektiği gibi oluşturulması ve kullanılması örgüt üyelerinin gerçek anlamda iş birliği ve iletişimi ile mümkün olup, çekişmelerden uzak olması önemlidir (Conklin, 2001). Bu konuyu daha geniş perspektiften ele alanlarda vardır. Ebbers ve Wijnberg'e göre (2009), örgütsel hafıza, bir şeylerin nasıl yapıldığına dair sadece bir bilgi deposu değil aynı zamanda organizasyonun üyelerinin karşı1ıklı olarak birbirlerinden ve hatta bütün organizasyondan beklentileridir. Robinson ve Ensign (2009) ise bu kapsama paydaşları da katmışlar ve güvene dayalı bir paydaş ilişkisi kurulup etkin bir bilgi paylaşımının örgütsel hafızanın rezervini geliştirdiğini öne sürmüşlerdir.

\section{HIPOTEZ GELIŞTIRME}

Araştırma, örgüt bünyesindeki kişi veya kişilerin aralarındaki gerilimin örgütsel hafızayı nasıl etkilediğini incelemeye yönelik kurgulanmıştır.

\section{1. İşte Kişilerarası Gerilimin Örgütsel Hafıza Üzerindeki Etkisi}

Örgütsel hafızaya değer verilmesi ve düzgün bir yönetim sistemi oluşturularak geliştirilmesi örgüt içerisinde iş ve yaşam faaliyetlerini iyileştirir (Rensburg, 2014). İş ortamında iş birliği ve iletişimin bilgi paylaşımını (Mei vd., 2004; Mäkelä \& Brewster, 2009; Jones III, 2017; Jones III, 2017) ve bilgi paylaşımının da örgütsel öğrenme (Senge, 2006; Camison \& Villar-Lopez, 2011) ve örgütsel hafızayı 
oluşturmada önemli bir faktör olduğu pek çok araştırmada vurgulanmıştır (Hult \& Ferrell, 1997; Conklin, 2001; Vrîncianu vd., 2009; Camisón \& Villar-López, 2011; Uğurlu, 2012). Örgütsel öğrenmenin örgütsel hafızayı güçlü bir şekilde etkilediği yapılan araştırmaların sonucunda belirlenmiştir (Hedberg, 1981; Walsh \& Ungson, 1991). Consiglio (2014) tarafindan 347 sağlık çalışanı üzerinde yapmış olduğu araştırmada kişilerarası gerilim ile duygusal uyumsuzluk arasında güçlü bir bağ olduğu sonucuna ulaşmıştır. Borgogni vd. (2012) İtalya'da 755 hastane çalışanı üzerinde yapmış oldukları ampirik çalışmada kişilerarası gerilimin kişilerarası etkileşimi azaltarak bilişsel uzaklık yarattığı görülmüştür. Daha önceki araştırmalarda doğrudan kişilerarası gerilimin örgütsel hafıza üzerindeki etkisine dair bir çalışmaya rastlanmamıştır. Ancak kişilerarası gerilimle olumsuz ilişki gösteren duygu durumlarının (kişilerarası iş birliği, iletişim ve bilgi paylaşımına açık olma) örgütsel hafızayı olumlu etkilediğine göre kişilerarası gerilimin örgütsel hafıza üzerinde olumsuz bir etkisi olabileceği varsayılmıştır. $\mathrm{Bu}$ nedenle kişilerarası gerilimin örgütsel hafıza üzerinde etkisi olup olmadığını belirlemek üzere araştırmada yalnız bir hipotez aşağıdaki gibi kurgulanmıştır.

H1: Kişilerarası gerilimin örgütsel hafıza üzerinde olumsuz ve anlamlı bir etkisi vardır.

\section{ARAŞTIRMANIN YÖNTEMI}

\section{1. Örneklem}

Tek aşamalı küme örnekleme yöntemi ile belirlenen araştırmanın örneklemini, Artvin İli Arhavi ilçesindeki okullarda görev yapan 321 öğretmen oluşturmaktadır. Okullara yapılan ziyaretlerle 200 öğretmene ulaşılarak anket formu dağıtılmış ve 128 anket formu dolu olarak geri dönmüştür. Buna göre araştırmaya katılım oranı \%64, ana kütlenin temsil oranı yaklaşık \%40 olarak gerçekleşmiştir. Araştırmadan önce Artvin Çoruh Üniversitesi Bilimsel Araştırma ve Yayın Etiği Kuruluna yapılan başvuru söz konusu Kurul tarafından değerlendirilmiş ve bu çalışmanın etik açıdan uygunluğu onaylanmıştır. Katılımcılar araştırma hakkında bilgilendirilmiş ve araştırmaya katılım gönüllülük esasıyla sağlanmıştır.

\subsection{Veri Toplama Aracı}

Araştırmada veri toplamak için kullanılan anket formu üç bölümden oluşmaktadır. Birinci bölüm demografik bilgiler, ikinci bölüm kişiler arası gerilim ölçeği, üçüncü bölüm ise örgütsel hafıza ölçeği olarak yapılandırılmıştır. Demografik bilgiler bölümü; cinsiyet, medeni durum, yaş, çalışma süresi (kıdem), öğrenim durumu, pozisyon, sosyal medya kullanım süresi ve kanalı, kurumsal sosyal medya gruplarına üyelik vb. durumlarına ilişkin olmak üzere toplam 11 sorudan oluşmaktadır. İşte kişiler arası gerilim ölçeği (Interpersonal Strain at Work), Borgogni, Armandi, Amaducci ve Consiglio (2007) tarafindan geliştirilmiş ve daha sonra Borgogni vd. (2012) tarafından 6 madde olarak revize edilmiş ve bu çalışma için uyarlanarak kullanılmıştır. Örgütsel hafiza ölçeğinin 5 maddesi (1-5. Maddeler) Uğurlu (2011) tarafindan ve diğer iki madde ise Hult \& Ferrell (1997) tarafından geliştirilmiş ölçeklerden uyarlanarak toplam 7 maddeden oluşmaktadır. Her iki ölçek de Likert tipi olarak yapılandırılmıştır (Kişiler arası gerilim: 1 = Hiçbir zaman, 5 = Günlük; Örgütsel hafıza: $1=$ Kesinlikle katılmıyorum, $5=$ Kesinlikle katılıyorum). Araştırmada elde edilen verilerin SPSS 25.0 istatistik programı ile betimleyici istatistikleri yapılmış ve aynı zamanda söz konusu veriler doğrusal regresyon yöntemleri ile analiz edilmiştir.

\section{BULGULAR}

Demografik verilerden elde edilen bulgulara göre araştırmaya 62 kadın (\%48.4) ve 66 erkek (51.6) katılmıştır. Katılımcıların; pozisyon olarak büyük çoğunluğunun \%79,7'sinin öğretmen, eğitim düzeyi olarak \%84.4'ünün lisans mezunu, medeni durum olarak \%77.3'ünün evli, yaş dağ 11 ımı olarak \%32.7'sinin 20-30 yaş arası ve \%22.7sinin 41-50 yaş arasında olduğu görülmüştür. Demografik bulgular Tablo 1'de gösterilmiştir. 
Tablo 1. Katılımciların demografik özellikleri

\begin{tabular}{|c|c|c|c|}
\hline Değişkenler & Gruplar & Say1 & Yüzde (\%) \\
\hline \multirow{4}{*}{ Bulundukları pozisyon } & Müdür & 9 & 7.0 \\
\hline & Müdür Yardımcısı & 17 & 12.3 \\
\hline & Öğretmen & 102 & 79.7 \\
\hline & Toplam & 128 & 100.0 \\
\hline \multirow{3}{*}{ Medeni Durumları } & Evli & 99 & 77.3 \\
\hline & Bekâr & 29 & 22.7 \\
\hline & Toplam & 128 & 100.0 \\
\hline \multirow{6}{*}{ Yaş Dağı̆lımı } & $20-30$ & 42 & 32.7 \\
\hline & $31-35$ & 20 & 15.6 \\
\hline & $36-40$ & 24 & 18.8 \\
\hline & $41-50$ & 29 & 22.7 \\
\hline & 51 yaşın üstü & 13 & 10.2 \\
\hline & Toplam & 128 & 100.0 \\
\hline \multirow{4}{*}{ Eğitim Durumları } & Ön lisans & 3 & 2.3 \\
\hline & Lisans & 108 & 84.4 \\
\hline & Yüksek lisans & 17 & 13.3 \\
\hline & Toplam & 128 & 100.0 \\
\hline \multirow{3}{*}{ Cinsiyet Dağılımı } & Erkek & 66 & 51.6 \\
\hline & Kadın & 62 & 48.4 \\
\hline & Toplam & 128 & 100.0 \\
\hline \multirow{6}{*}{ Aylık Gelir Durumu } & 3000 TL ve alt 1 & 33 & 25.8 \\
\hline & $3.001-5.000 \mathrm{TL}$ & 87 & 68.0 \\
\hline & $5.001-6.000 \mathrm{TL}$ & 5 & 3.9 \\
\hline & $6.001-7.000 \mathrm{TL}$ & 1 & 0.8 \\
\hline & 7.001 TL ve üzeri & 2 & 1.6 \\
\hline & Toplam & 128 & 100.0 \\
\hline
\end{tabular}

Demografik sorulardan üçü de katılımcıların kullandıkları sosyal medya uygulamaları, sosyal medya kullanım süreleri ve meslektaşların sosyal medya gruplarına üyelik durumu ile ilgilidir. Araştırmada katılımcıların sırasıyla Facebook (\%29.7), Instagram (\%28.9) ve WhatsApp'ın (\%25.8) en çok kullandıkları sosyal ağlar olduğu belirlenmiştir. Sosyal medyada geçirilen süre bakımından bir gün içinde 30 dakika ile 1 saat arası zaman geçirenlerin en yüksek oranda (\%37.5) olduğu görülmüştür. Araştırmaya katılanların sosyal medyadaki aktiviteleri ilgili veriler Tablo 2'de gösterilmiştir.

Tablo 2. Katılımcıların sosyal medya kullanım eğilimleri

\begin{tabular}{|c|c|c|c|}
\hline Değişkenler & Gruplar & Say1 & Yüzde (\%) \\
\hline \multirow{6}{*}{ En çok kullanılan sosyal ağ } & Facebook & 38 & 29.7 \\
\hline & Twitter & 15 & 11.7 \\
\hline & Instagram & 37 & 28.9 \\
\hline & WhatsApp & 33 & 25.8 \\
\hline & Youtube & 5 & 3.9 \\
\hline & Toplam & 128 & 100.0 \\
\hline \multirow{3}{*}{ Meslektaşların sosyal medya grubuna üyelik } & Evet var & 105 & 82.0 \\
\hline & Hayır yok & 23 & 18.0 \\
\hline & Toplam & 128 & 100.0 \\
\hline \multirow{8}{*}{ Sosyal medyada bir günde geçirilen toplam süre } & 10 dakikadan az & 5 & 3.8 \\
\hline & 10 dakika ile 30 dakika arası & 27 & 21.1 \\
\hline & 30 dakika ile 1 saat arası & 48 & 37.5 \\
\hline & 1 saat ile 2 saat aras 1 & 21 & 16.4 \\
\hline & 2 saat ile 3 saat aras 1 & 13 & 10.2 \\
\hline & 3 saat ile 4 saat arası & 7 & 5.5 \\
\hline & 4 saatten fazla & 7 & 5.5 \\
\hline & Toplam & 128 & 100.0 \\
\hline
\end{tabular}




\subsection{Geçerlilik ve Güvenilirlik Analizi}

Araştırmada kullanılan örneklemin yeterliliği için Kaiser-Meyer-Olkin (KMO) değerlerinin 0.50 ve üzeri olması, Bartlett's küresellik testinde sonucun istatistiksel olarak anlamlı olması, değiş̧kenlerin faktör yüklerinin 0.400'ün üzerinde olması gerekir (Sharma, 1996; Field, 2009). Kişilerarası gerilim ölçeğinin KMO değerinin $0.719(p<0.001)$ ve değişkenlerinin faktör yüklerinin 0.415-0.799 arasında olduğu görülmüştür. Araştırmada yer alan örgütsel hafıza ölçeğinin KMO değerinin $0.776(p<0.001)$, ölçek değişkenlerinin faktör yüklerinin 0.543-0.770 arasında olduğu belirlenmiştir. Araştırmanın güvenilirliği için ölçekte yer alan her bir maddenin Cronbach's Alpha değerinin 0.70 veya üzerinde olması yeterlidir (Nunally, 1978; Field, 2009). Güvenilirlik testi sonucunda Cronbach's Alpha değerleri; kişilerarası gerilim ölçeğinin 0.739 ve örgütsel hafiza ölçeğinin ise 0.760 olduğu görülmüştür. Örgütsel hafiza ölçeğinden güvenilirlik analizinde 7. Madde (İş yapma sürecinde yapmış olduğumuz hatalı durumları ortaya çıkarmak için kullandığımız programlar var) güvenilirlik düzeyi düşük olduğu için analizden çıkarılmıştır. Tablo 3'de gösterilen analiz sonuçlarından ölçekler ve örneklemin geçerliliğinin ve güvenilirliğinin sağlandığı anlaşılmıştır.

Tablo 3. Araştırmanın faktör, geçerlilik ve güvenilirlik sonuçları

\begin{tabular}{|c|c|c|c|c|c|c|}
\hline Ölçekler & $\begin{array}{l}\text { Cronbach's Alpha } \\
\qquad(\alpha)\end{array}$ & KMO & Yakl. $\chi^{2^{*}}$ & SD & $\begin{array}{l}\text { Varyans } \\
\%\end{array}$ & $p$ \\
\hline Kişilerarası gerilim & .739 & .719 & 176.770 & 15 & 45.071 & .000 \\
\hline Örgütsel hafiza & .760 & .776 & 185.623 & 15 & 48.175 & .000 \\
\hline \multicolumn{2}{|c|}{ Kişilerarası gerilim değişkenleri } & Faktör Yükü & \multicolumn{3}{|c|}{ Örgütsel hafiza değişkenleri } & Faktör Yükü \\
\hline \multicolumn{2}{|c|}{$\begin{array}{l}\text { 1. İşyerinde, diğerlerinden uzak kaldığımda } \\
\text { kendimi daha iyi hissediyorum. }\end{array}$} & .799 & \multicolumn{3}{|c|}{$\begin{array}{l}\text { 1. Kurumumuzda aynı hata sik sik tekrar } \\
\text { edilir. }\end{array}$} & .543 \\
\hline \multicolumn{2}{|c|}{$\begin{array}{l}\text { 2. İş yerinde kendimi diğer insanların sorunlarına } \\
\text { karşı duyarsız buluyorum. }\end{array}$} & .768 & \multicolumn{3}{|c|}{$\begin{array}{l}\text { 2. Kurumumuzda deneyimler ve } \\
\text { tecrübeler genellikle kayıt altına alınır. }\end{array}$} & .737 \\
\hline \multicolumn{2}{|c|}{$\begin{array}{l}\text { 3. İş yerinde başkalarına karşı soğuk ve mesafeli } \\
\text { davranıyorum. }\end{array}$} & .774 & \multicolumn{3}{|c|}{$\begin{array}{l}\text { 3. Kurumumuzda bir grup veya birimde } \\
\text { gerçekleşen öğrenme diğer birimlere } \\
\text { de yayılır. }\end{array}$} & .753 \\
\hline \multicolumn{2}{|c|}{$\begin{array}{l}\text { 4. İşyerinde özellikle başkalarına ne olduğuyla } \\
\text { ilgilenmiyorum. }\end{array}$} & .692 & \multicolumn{3}{|c|}{$\begin{array}{l}\text { 4. Kurumumuzda öğrenme bireysel } \\
\text { düzeyde gerçekleşir, örgütsel öğrenme } \\
\text { düzeyine ulaşmaz. }\end{array}$} & .691 \\
\hline \multicolumn{2}{|c|}{ 5. Bazen çalışırken, birine kötü davrandığım olur. } & .415 & \multicolumn{3}{|c|}{$\begin{array}{l}\text { 5. Kurumumuzda, eylemlerimizin } \\
\text { örgütsel amaçlarla uyumlu olduğunu } \\
\text { düşünüyoruz. }\end{array}$} & .645 \\
\hline \multicolumn{2}{|c|}{$\begin{array}{l}\text { 6. İşyerinde diğer insanlar tarafından rahatsız } \\
\text { ediliyorum. }\end{array}$} & .474 & \multicolumn{3}{|c|}{$\begin{array}{l}\text { 6. Geçmişten çıkarılan derslerin canlı } \\
\text { tutulduğu güzel bir muhabbet ortamı } \\
\text { vardır. }\end{array}$} & .770 \\
\hline
\end{tabular}

* Yaklaşık Ki-kare.

\subsection{Korelasyon Analizi}

Kişilerarası gerilim ve örgütsel hafıza arasındaki anlamlı ve negatif korelasyon değeri $(r=-.436, p<.001)$ ve bu ölçeklerin aritmetik ortalamaları ve standart sapmaları Tablo 4'te gösterilmiştir. Bu sonuca göre kişilerarası gerilim azaldıkça örgütsel hafıza olumlu etkilenmekte ve artmaktadır.

Tablo 4. Aritmetik ortalama, standart sapma ve korelasyon değerleri

\begin{tabular}{lcccc}
\hline Ölçekler & AO & SS & 1 & 2 \\
\hline 1. Kişilerarası gerilim & 1.96 & .68 & 1 & \\
2. Örgütsel hafıza & 3.40 & .69 & $-.436^{*}$ & 1 \\
\hline
\end{tabular}

* Korelasyon $p<0.001$ düzeyinde anlamlıdır (2-tailed). $(\mathrm{N}=128)$ 


\subsection{Betimleyici İstatistikler}

Ankette yer alan maddeler 1-5 aralığında Likert yöntemiyle değerlendirildiğinden aynı aralıkta aritmetik ortalamalara bağlı puan aralığı katsayısı hesaplanarak aralıkta yer alan her bir ölçek rakamına eklenmiştir. Hesaplamada, en yüksek Likert puan 5'ten en düşük puan 1 çıkarılarak kalan 4 puanı en yüksek puana bölünmüş ve bulunan 0.80 katsayısı her bir Likert değerine eklenmiştir. Böylece derecelendirme aralıkları oluşturulmuştur (1.00-1.80=Çok düşük; 1.81-2.60=düşük; 2.61-3.40=orta; 3.41-4.20=yüksek; 4.21$5.00=$ çok yüksek).

Katılımcıların kişiler arası gerilime ilişkin algılarının ortalama değerleri Tablo 5 'te gösterilmiştir. Ölçekteki maddelerden "İşyerinde, diğerlerinden uzak kaldığımda kendimi daha iyi hissediyorum” en yüksek ortalama değerine $(M=2.23)$ sahip iken "İşyerinde diğer insanlar tarafindan rahatsız ediliyorum" maddesi en düşük ortalama değerini almıştır $(M=1.69)$. Bu sonuçlar, katılımcıların iş arkadaşları ile ilişkilerinde düşük düzeyde kişiler arası gerilim algısına sahip olduklarını göstermiştir.

Tablo 5. Kişiler arası gerilim maddeleri ve betimleyici istatistikleri

\begin{tabular}{|c|c|c|c|c|c|c|c|c|c|c|}
\hline Ölçek maddeleri & & $\mathrm{AO} / \mathrm{SS}$ & Düzey & $\begin{array}{l}\mathrm{F} \\
\%\end{array}$ & 1 & 2 & 3 & 4 & 5 & Toplam \\
\hline \multirow{2}{*}{$\begin{array}{l}\text { 1. İşyerinde, diğerlerinden uzak kaldığımda } \\
\text { kendimi daha iyi hissediyorum. }\end{array}$} & $\mathrm{AO}$ & 2.23 & \multirow{2}{*}{ Düşük } & $\mathrm{F}$ & 38 & 43 & 31 & 12 & 4 & 128 \\
\hline & SS & 1.08 & & $\%$ & 29.7 & 33.6 & 24.2 & 9.4 & 3.1 & 100 \\
\hline \multirow{2}{*}{$\begin{array}{l}\text { 2. İş yerinde kendimi diğer insanların } \\
\text { sorunlarına karşı duyarsız buluyorum. }\end{array}$} & $\mathrm{AO}$ & 1.77 & \multirow{2}{*}{$\begin{array}{l}\text { Çok } \\
\text { düşük }\end{array}$} & $\mathrm{F}$ & 54 & 53 & 15 & 5 & 1 & 128 \\
\hline & SS & 0.83 & & $\%$ & 42.2 & 41.4 & 11.7 & 3.9 & 0.8 & 100 \\
\hline \multirow{3}{*}{$\begin{array}{l}\text { 3. İş yerinde başkalarına karşı soğuk ve mesafeli } \\
\text { davranıyorum. }\end{array}$} & $\mathrm{AO}$ & 2.02 & \multirow{2}{*}{ Düşük } & $\mathrm{F}$ & 48 & 47 & 19 & 10 & 4 & 128 \\
\hline & SS & 1.07 & & $\%$ & 37.5 & 36.7 & 14.8 & 7.8 & 3.1 & 100 \\
\hline & $\mathrm{AO}$ & 2.10 & \multirow{2}{*}{ Düşük } & $\mathrm{F}$ & 46 & 47 & 15 & 14 & 6 & 128 \\
\hline $\begin{array}{l}\text { 4. İşyerinde özellikle başkalarına ne olduğuyla } \\
\text { ilgilenmiyorum. }\end{array}$ & SS & 1.15 & & $\%$ & 35.9 & 36.7 & 11.7 & 10.9 & 4.7 & 100 \\
\hline \multirow{2}{*}{$\begin{array}{l}\text { 5. Bazen çalışırken, birine kötü davrandığım } \\
\text { olur. }\end{array}$} & $\mathrm{AO}$ & 1.94 & \multirow{2}{*}{ Düşük } & $\mathrm{F}$ & 55 & 42 & 16 & 13 & 2 & 128 \\
\hline & SS & 1.06 & & $\%$ & 43.0 & 32.8 & 12.5 & 10.2 & 1.6 & 100 \\
\hline \multirow{2}{*}{$\begin{array}{l}\text { 6. İşyerinde diğer insanlar tarafından rahatsız } \\
\text { ediliyorum. }\end{array}$} & $\mathrm{AO}$ & 1.69 & \multirow{2}{*}{$\begin{array}{l}\text { Çok } \\
\text { düşük }\end{array}$} & $\mathrm{F}$ & 70 & 40 & 7 & 7 & 4 & 128 \\
\hline & SS & 1.00 & & $\%$ & 54.7 & 31.3 & 5.5 & 5.5 & 3.1 & 100 \\
\hline
\end{tabular}

$\mathrm{AO}=$ Aritmetik Ortalama, $\mathrm{SS}=$ Standard Sapma, $\mathrm{F}=$ Frekans,

(1=Hiçbir zaman, 2=Nadiren, 3=Bazen, 4=Sık sık, 5=Her gün)

Aynı yöntem ile hesaplanan katılımcıların örgütsel hafızaya ilişkin algılarının ortalama değerleri Tablo 6'da gösterilmiştir. Örgütsel hafiza ölçeğindeki maddelerden "Kurumumuzda öğrenme bireysel düzeyde gerçekleşir, örgütsel öğrenme düzeyine ulaşmaz" en yüksek ortalama değerine $(M=3.53)$ sahip iken "Kurumumuzda deneyimler ve tecrübeler genellikle kayıt altına alınır" maddesi en düşük ortalama değerini almıştır $(M=3.23)$. Analiz sonuçları, katılımcıların örgütsel hafıza algılarının ortalamanın üzerinde $(M=$ 3.40) bir düzeyde olduğunu göstermiştir. Ortalamanın üzerinde hatta yüksek kabul edilebilecek düzeyde örgütsel hafıza algısına karşılık düşük düzeyde kişiler arası gerilim algısı betimleyici istatistik sonuçlarının korelasyon sonuçları ile tutarlı olduğunu ortaya koymuştur. 
Tablo 6. Örgütsel hafıza maddeleri ve betimleyici istatistikleri

\begin{tabular}{|c|c|c|c|c|c|c|c|c|c|c|}
\hline Ölçek maddeleri & \multicolumn{2}{|c|}{$\mathrm{AO} / \mathrm{SS}$} & Düzey & $\begin{array}{l}\mathrm{F} \\
\%\end{array}$ & 1 & 2 & 3 & 4 & 5 & Toplam \\
\hline \multirow{2}{*}{ 1. Kurumumuzda aynı hata sık sik tekrar edilir. } & $\mathrm{AO}$ & 3.43 & \multirow{2}{*}{ Yüksek } & $\mathrm{F}$ & 10 & 17 & 31 & 48 & 22 & 128 \\
\hline & SS & 1.14 & & $\%$ & 7.8 & 13.3 & 24.2 & 37.5 & 17.2 & 100 \\
\hline \multirow{2}{*}{$\begin{array}{l}\text { 2. Kurumumuzda deneyimler ve tecrübeler } \\
\text { genellikle kayıt altına alınır. }\end{array}$} & $\mathrm{AO}$ & 3.23 & \multirow{2}{*}{ Orta } & $\mathrm{F}$ & 7 & 17 & 55 & 39 & 10 & 128 \\
\hline & SS & 0.95 & & $\%$ & 5.5 & 13.2 & 43.0 & 30.5 & 7.8 & 100 \\
\hline \multirow{2}{*}{$\begin{array}{l}\text { 3. Kurumumuzda bir grup veya birimde } \\
\text { gerçekleşen öğrenme diğer birimlere de } \\
\text { yayılır. }\end{array}$} & $\mathrm{AO}$ & 3.49 & \multirow{2}{*}{ Yüksek } & $\mathrm{F}$ & 5 & 11 & 39 & 62 & 11 & 128 \\
\hline & SS & 0.88 & & $\%$ & 3.9 & 8.6 & 30.5 & 48.4 & 8.6 & 100 \\
\hline \multirow{2}{*}{$\begin{array}{l}\text { 4. Kurumumuzda öğrenme bireysel düzeyde } \\
\text { gerçekleşir, örgütsel öğrenme düzeyine } \\
\text { ulaşmaz. }\end{array}$} & $\mathrm{AO}$ & 3.53 & \multirow{2}{*}{ Yüksek } & $\mathrm{F}$ & 4 & 12 & 42 & 53 & 17 & 128 \\
\hline & SS & 0.92 & & $\%$ & 3.1 & 9.4 & 32.8 & 41.4 & 13.3 & 100 \\
\hline \multirow{2}{*}{$\begin{array}{l}\text { 5. Kurumumuzda, eylemlerimizin örgütsel } \\
\text { amaçlarla uyumlu olduğunu düşünüyoruz. }\end{array}$} & $\mathrm{AO}$ & 3.33 & \multirow{2}{*}{ Orta } & $\mathrm{F}$ & 8 & 13 & 44 & 55 & 8 & 128 \\
\hline & SS & 0.95 & & $\%$ & 6.3 & 10.2 & 34.4 & 43.0 & 6.3 & 100 \\
\hline \multirow{2}{*}{$\begin{array}{l}\text { 6. Geçmişten çıkarılan derslerin canlı tutulduğu } \\
\text { güzel bir muhabbet ortamı vardır. }\end{array}$} & $\mathrm{AO}$ & 3.39 & \multirow{2}{*}{ Orta } & $\mathrm{F}$ & 10 & 12 & 37 & 56 & 13 & 128 \\
\hline & SS & 1.04 & & $\%$ & 7.8 & 9.4 & 28.9 & 43.7 & 10.2 & 100 \\
\hline
\end{tabular}

$\mathrm{AO}=$ Aritmetik Ortalama, $\mathrm{SS}=$ Standard Sapma, F=Frekans,

(1=Kesinlikle katılmıyorum, 2= Katılmıyorum, 3=Kararsızım, 4= Katılıyorum, 5= Kesinlikle kat1liyorum).

\subsection{Doğrusal Regresyon}

Kişilerarası gerilimin örgütsel hafıza üzerinde etkisinin olup olmadığını belirlemek için doğrusal regresyon analizi yapılmıştır. Sonuçlar, kişilerarası gerilimin örgütsel hafıza üzerinde anlamlı ve olumsuz etkisi olduğunu göstermiştir $(\beta=-.436, p<.001)$. Bu sonuca göre araştırmanın hipotezi (H1: Kişilerarası gerilimin örgütsel hafıza üzerinde olumsuz ve anlamlı etkisi vardır) kabul edilmiştir. Analizdeki $R^{2}$ değerine göre örgütsel hafızadaki olumsuz değişimin \%19'u kişilerarası gerilim tarafindan açıklanmaktadır $\left(R^{2}=.190\right.$, $p<.001)$. Standard beta değeri $(\beta=-.436)$, kişilerarası gerilimdeki bir birimlik değişimin örgütsel hafizada 0.436 birim azalış (negatif olduğu için) olacağını göstermektedir. Regresyon analizi sonuçları Tablo 7'de gösterilmiştir.

Tablo 7. Doğrusal Regresyon Analizi Sonuçları

\begin{tabular}{lllllllll}
\hline Bağımsız değişken & $\mathrm{B}$ & $\mathrm{SE}$ & $\beta$ & $F$ & $R^{2}$ & $t$ & $p$ & $\mathrm{DW}$ \\
\hline $\begin{array}{l}\text { Kişilerarası } \\
\text { gerilim }\end{array}$ & -.438 & .083 & -.436 & 27.870 & .190 & -5.279 & .000 & 1.867 \\
\hline
\end{tabular}

Bağımlı değişken = Örgütsel Hafıza; SE = Standard hata; DW = Durbin Watson.

\section{SONUÇ}

Örgütsel ilişkiler ve bunlara bağlı örgütsel etkileşimler çok değişik faktörlerle ilişkilendirilerek daha önce araştırma konusu olmuştur. Ancak örgütlerde iş ortamlarında sıkça görülen kişilerarası gerilim durumunun örgüt için en önemli unsurlardan biri olan örgütsel hafıza üzerindeki etkisine yönelik literatürde bir çalışmaya rastlanmamış olması bu alanda bir araştırma yapma gereğini ortaya çıkarmıştır. Bu çalışmanın amacı belirlenen açığı gidermek için işte kişilerarası gerilimin örgütsel hafıza üzerinde etkisinin olup olmadığı, etkisi varsa bu etkinin yönünün belirlenmesidir. Yapılan korelasyon analizinde işte kişilerarası gerilim ile örgütsel hafızanın negatif korelasyona sahip oldukları belirlenmiştir $(r=-.436 ; p>.001)$. Çalışma kapsamında işte kişilerarası gerilim ölçeğine verilen cevapların betimleyici analiz sonuçlarına göre katılımcıların işyerinde, diğerlerinden uzak kaldığında kendilerini daha iyi hissettikleri anlaşılmıştır. Bu 
sonuç yüksek ortalamaya sahip olmamakla birlikte ortalama düzeyi olarak diğer maddelerden istatistiksel olarak yüksek olduğu görülmüsstür $(M=2.23)$. Araştırma kapsamında katılımcılara yöneltilen örgütsel hafiza ölçeğinde ise katılımcıların kurumlarında öğrenmenin bireysel düzeyde gerçekleştiği, örgütsel öğrenme düzeyine ulaşmadığı şeklinde görüş belirttikleri ortaya çıkmıştır $(M=3.53)$. Aynı zamanda katılımcıların, kurumlarında deneyimlerin ve tecrübelerin genellikle kayıt altına alındığı yönündeki görüşlerinin de ortalamanın üzerinde bir değer almasına karşın aynı ölçekte yer alan diğer maddelere göre nispeten düşük ortalama değere sahiptir $(M=3.23)$. Regresyon analizi sonucunda işte kişilerarası gerilimin örgütsel hafıza üzerinde olumsuz ve anlamlı bir etkisi olduğu belirlenmiştir $(\beta=-.436 ; p>.001)$. Araştırmada yapılan korelasyon testinin ve regresyon testinin sonucunun birbirleri ile tutarlı olduğu görülmüştür. Bu sonuç, işte kişilerarası gerilimin bir birimlik artışı örgütsel hafızanın 0.436 düzeyinde (başka bir ifade ile \%43.6 oranında) azalması/olumsuz etkilenmesi olarak değerlendirilmiştir. Araştırmanın sonucu yorumlandığında organizasyonlarda her düzeyde yöneticinin örgüt içerisinde hem bireyler hem de gruplar arasında herhangi bir gerilime yol açacak söz ve eylemlerden kaçınılmasını sağlamaları önerilmektedir. Böyle yaparak, örgütsel hafızanın oluşmasını ve güçlenmesini engelleyecek durumları ortadan kaldıracaklarının bilincinde olmaları gerekir. Çalışanlar arasında herhangi bir gerilim yaşanması halinde çatışma çözüm yöntemlerinden uygun olanları uygulanarak önlenmesi gerekir.

İşte kişilerarası gerilimin örgütsel hafıza üzerindeki etkisi veya aralarındaki ilişkiye dair daha önce yapılmış bir çalışmaya rastlanmadığından bu sonuçların önceki çalışmalarla karşılaştırma ve tartışma imkânı da olmamıştır. Bu çalışmanın katılımcı sayısının az olması ve kısıtlı bölgede yapılmış olması sonucun genellenmesine engel olarak görülebilir. Gelecekte yapılacak çalışmaların daha çok sayıda ve değişik bölgelerdeki katılımcılarla yapılması önerilmektedir.

Etik Kurul Onayı: Bu araştırmada kullanılan yöntem ve veri toplama araçları için Artvin Çoruh Üniversitesi Bilimsel Araştırma ve Yayın Etiği Kurulun'dan 24.06.2020 tarihli ve 2020/9 numaralı karar ile etik kurul onayı alınmıştır.

Çatışma Beyanı Yazarlar arasında herhangi bir çıkar çatışması yoktur.

\section{KAYNAKLAR}

Anand, V., Manz, C. C. \& Glick, W. H. (1998). An organizational memory approach to information management. The Academy of Management Review, 23(4), 796-809. https://doi.org/10.2307/259063

Abraham, R. (1998). Emotional dissonance in organizations: antecedents, consequences and moderators. Genetic, Social, and General Psychology Monographs, 124, 229-246.

Bencsik, A., Löre, V. \& Marosi, I. (2009). From individual memory to organizational memory (intelligence of organizations). International Scholarly and Scientific Research \& Innovation 3(8), 1699-1704.

Borgogni, L., Armandi, F., Amaducci, M. \& Consiglio, C. (2007). Integrazione alla misura del Job Burnout: la scala di Sovraccarico Relazionale. Giornale Italiano di Psicologia, 3, 699-711. https://doi.org/10.1421/25225

Borgogni, L., Consiglio, C., Alessandri, G. \& Schaufeli, W. B. (2012). Don't throw the baby out with the bathwater! Interpersonal strain at work and burnout. European Journal of Work and Organizational Psychology, 21(6), 875-898, https://doi.org/10.1080/1359432X.2011.598653.

Camisón, C. \& Villar-López, A. (2011). Non-technical innovation: Organizational memory and learning capabilities as antecedent factors with effects on sustained competitive advantage. Industrial Marketing Management, 40(8), 1294-1304. https://doi.org/10.1016/j.indmarman.2011.10.001

Caughlin, J. P. \& Huston, T. L. (2002). A contextual analysis of the association between demand/withdraw and marital satisfaction. Personal Relationships, 9(1), 95-119. https://doi.org/10.1111/1475-6811.00007

Conklin, J. (2001). Designing organizational memory: Preserving intellectual assets in a knowledge economy. In Institute, C. (ed.), Designing organizational memory (pp. 2-41). Los Angeles, CA.: CogNexus Institute.

Consiglio, C. (2014). Interpersonal strain at work: A new burnout facet relevant for the health of hospital staff. Burnout Research, 1(2), 69-75. https://doi.org/10.1016/j.burn.2014.07.002. 
Ebbers, J. J. \& Wijnberg, N. W. (2009). Organizational memory: From expectations memory to procedural memory. British Journal of Management, 20, 478-490. https://doi.org/10.1111/j.1467-8551.2008.00603.x

Eldridge, K. A. \& Christensen, A. (2002). Demand-withdraw communication during couple conflict: A review and analysis. In P. Noller \& J. A. Feeney (Eds.), Understanding marriage: Developments in the study of couple interaction (ss. 289-322). Cambridge University Press.

Field, A. (2009). Discovering Statistics Using SPSS. Third edition. SAGE Publications.

Hedberg, B. (1981). How Organizations learn and unlearn. In Nystrom, P., Starbuck, W. (Eds.), Handbook of organizational design: Adapting organisations to their environment (pp. 1-27), Oxford: Oxford University Press.

Hanvanich, S., Sivakumar, K. \& Hult, G. T. M. (2006). The relationship of learning and memory with organizational performance: The moderating role of turbulence. Journal of the Academy of Marketing Science, 34(4), 600612. https://doi.org/10.1177/0092070306287327

Hochschild, A. R. (2012). The managed heart: Commercialization of human feeling. University of California Press.

Hult, G. T. M. \& Ferrell, O. C. (1997). Global organizational learning capacity in purchasing: Construct and measurement. Journal of Business Research, 40(2), 97-111. https://doi.org/10.1016/S0148-2963(96)00232-9.

Jackson, P. (2010). From function to use. In Jackson, P. (Ed.), Web 2.0 Knowledge Technologies and the Enterprise (pp. 155-196), Chandos Publishing. https://doi.org/10.1016/B978-1-84334-537-4.50006-5.

Jasimuddin, S. M., Connell, N. A. D. \& Klein, J. (2009). Understanding organizational memory. In Schwartz, D. \& Te'eni, D. (Eds.), Encyclopedia of Knowledge Management (pp. 1536-1545). IGI Global., https://doi.org/10.4018/9781599049335.ch014

Jennex, M. E. \& Olfman, L. (2004). Organizational memory. In Holsapple, C.W. (Ed.), Handbook on knowledge management 1. International handbooks on information systems (pp 207-234). Springer. https://doi.org/10.1007/978-3-540-24746-3_11.

Jerez-Gómez, P., Céspedes-Lorente, J. \& Valle-Cabrera, R. (2005). Organizational learning capability: A proposal of measurement. Journal of Business Research, 58(6), 715-725. https://doi.org/10.1016/j.jbusres.2003.11.002.

Jones III, D.M. G. E. (2017) Knowledge sharing and technological innovation: The effectiveness of trust, training, and good communication, Cogent Business \& Management, 4(1), 1387958. https://doi.org/10.1080/23311975.2017.1387958.

Leiter, M. P. \& Maslach, C. (2016). Latent burnout profiles: A new approach to understanding the burnout experience. Burnout Research 3(4) 89-100. https://doi.org/10.1016/j.burn.2016.09.001

Mäkelä, K. \& Brewster, C. (2009). Interunit interaction contexts, interpersonal social capital, and the differing levels of knowledge sharing. Human Resource Management, 48(4), 591-613. https://doi.org/10.1002/hrm.20300

Maslach, C., Schaufeli, W. B. \& Leiter, M. P. (2001). Job burnout. Annual Review of Psychology, 52, $397-422$.

Mei, Y. M., Lee, S. T. \& Al-Hawamdeh, S. (2004). Formulating a Communication Strategy for Effective Knowledge Sharing. Journal of Information Science, 30(1), 1222. https://doi.org/10.1177/0165551504041674

Moorman, C. \& Miner, A. S. (1997). The impact of organizational memory on new product performance and creativity. Journal of Marketing Research, 34(1), pp. 91-106. https://doi.org/10.1177/002224379703400108

Nunnally, J.C. (1978). Psychometric Theory. McGraw-Hill.

Olusa, A. O. \& Afolabi, O. A. (2017). Job demand and job involvement among employees in construction and manufacturing industries: Mediating role of occupational burnout. International Journal of Applied Psychology, 7(1), 19-28. https://doi.org/10.5923/j.ijap.20170701.03

Read, E. \& Read, A. (2018). Harnessing the power of positive social capital at work to combat workplace aggression. In Burke, R. J., Cooper, C. L. (Eds.), Violence and Abuse In and Around Organisations (pp. 458482), Routledge.

Rensburg, J. van M.S. (2014). Using organisational memory in evaluations'. African Evaluation Journal 2(1), Art. \#75, 9 pages. http://dx.doi.org/10.4102/aej.v2i1.75 
Rutter, D. R. \& Fielding, P. J. (1988). Sources of occupational stress: an examination of British prison officers. Work and Stress, 2, 291-299. https://doi.org/10.1080/02678378808257490.

Robinson, N. P. \& Ensign, P. C. (2009). Effective stakeholder knowledge sharing for effective organizational memory. In Girard, J. P. (Ed.), Building organizational memories: Will you know what you knew? (pp. 3043), New York: IGI Publishing. https://doi.org/10.4018/978-1-59904-540-5.ch003

Salanova, M. \& Schaufeli, W. B. (2000). Exposure to technology and its relationship to burnout. Behavior and Information Technology, 19, 385-392.

Senge, P. M. (2006). The fifth discipline: The Art \& Practice of the learning organization. Revised \& Updated edition. Doubleday.

Sharma, S. (1996). Applied Multivariate Techniques. John Wiley and Sons Inc.

Te'eni, D. (2011). Knowledge for communicating knowledge. In Schwartz, D., Te'eni, D. (Eds.), Encyclopedia of Knowledge Management, (pp. 560-569), London: IGI Global. https://doi.org/10.4018/978-1-59904-9311.ch054

Tsai, H.M.-T. (2008). "The influences of organizational memory and market information processes on product innovation," 2008 4th IEEE International Conference on Management of Innovation and Technology, Bangkok, pp. 397-401, https://doi.org/10.1109/ICMIT.2008.4654397.

Uğurlu, Ö. Y. (2011). Örgütsel öğrenme yeteneğinin ürün yeniliği performansına etkisi: üretim işletmelerinde bir araştırma (Yayımlanmamış doktora tezi). Afyon Kocatepe Üniversitesi, Sosyal Bilimler Enstitüsü, Afyonkarahisar.

Walsh, J. P. \& Ungson, G. R. (1991). Organizational memory. The Academy of Management Review, 16(1), 5791. https://doi.org/10.2307/258607

Vrîncianu, M., Anica-Popa, L. \& Anica-Popa, I. (2009). Organizational Memory: an Approach from Knowledge Management and Quality Management of Organizational Learning Perspectives. The Amfiteatru Economic Journal, 11(26), 473-481.

Zapf, D. (2002). Emotion work and psychological well-being: A review of the literature and some conceptual considerations. Human Resource Management Review, 12, 237-268. https://doi.org/10.1016/S10534822(02)00048-7

Zapf, D. \& Holz, M. (2006). On the positive and negative effects of emotion workin organizations. European Journal of Work \& Organizational Psychology, 15(1), 1-28. https://doi.org/10.1080/1 